\title{
USE OF A DEMOGRAPHIC BASE MAP FOR THE PRESENTATION OF AREAL DATA IN EPIDEMIOLOGY
}

\author{
BY \\ F. FORSTER \\ Research Scholar, Department of Social Medicine, University of Edinburgh
}

The purpose of this article is to offer a development of the demographic map as an alternative to the geographical base-map for the presentation of areal data in epidemiology. The results of geographical investigations into disease morbidity or mortality are often presented cartographically and invariably the base-map used is the normal geographical one, showing the relevant administrative areas. The relating of disease rates to area is useful, in that the recognition of areas characterized by high or low rates may lead to clues of aetiological significance.

When considering areal patterns of disease, however, the epidemiologist requires information about the size of the population at risk in the areas concerned. Sutherland (1962) drew attention to the principal deficiency of the geographical base-map in this respect. Referring to Scotland, he showed that on the normal map correct weighting could not be given to the large urban populations which occupy small areas, whilst small rural populations, often sparsely distributed over large areas, could appear to be over-represented. Thus, base-maps which would relate disease rates to the local populations at risk as well as to geographical position might prove useful epidemiological tools. Development of the demographic map, in which the area of each administrative unit is made proportional to its population whilst contiguity of geographical boundaries and the relative geographical positions of the units are maintained as far as is possible (Hollingsworth, 1966) offers interesting possibilities in this direction.

The use of such maps in epidemiology is not new, Levison and Haddon (1965), for example, having used the technique for plotting cases of Wilm's tumour in New York State. To date, however, these maps have not been used to present data at the national level.
Sutherland (1962) developed a form of demographic diagram, using the same principle of area proportional to population, called an isodemic representation. As a basis he split Scotland into its five hospital regions and showed them separated. He thus lost geographical contiguity between the administrative units, a condition it would seem desirable to preserve.

An attempt has been made in developing the agesex specific cartograms illustrated below (Figs 1, 3 , and 4) to relate disease rates to both the population at risk and to geographical position in the 57 public health districts of Scotland.* A basic aim was also to try to produce cartograms similar to each other in local outline as well as in overall shape to make them readily comparable and hence of greater potential utility. Efforts to simplify their construction and final shape have also been made. To date demographic maps have presented complicated construction problems and their final appearance has often been of considerable complexity. These factors may well have obscured their advantages and contributed to their limited application so far.

\section{MethoD}

Levison and Haddon (1965) outlined their procedure for constructing a demographic map or, as they called it, an "area adjusted map" of New York State. As there is no unique solution for a given area and population, and because conventions are developed as one proceeds which require explanation, an account of the method of construction used here is given below. Reference to the locational cartogram (Fig. 1, overleaf) based on the 1961 female

\footnotetext{
* The insular portions of Inverness and Ross and Cromarty Counties, treated as separate public health districts by the Registrar General for Scotland, have been considered as part of their parent counties here, thus reducing the number of districts from 59 to 57 .
} 
Zetlond $C$.

Orkney $C$.

COUNTY OF CITY

AND LARGE BURGH sutherlond $C$. Caithness $C$.

BOUNDARY

NON-CONTIGUOUS

BOUNDARY

I. MORAY FIRTH

2. FIRTH OF TAY

3. FIRTH OF FORTH

4. FIRTH OF CLYDE

c. of C. COUNTY OF

C. COUNTY

L.B. LARGE BURGH
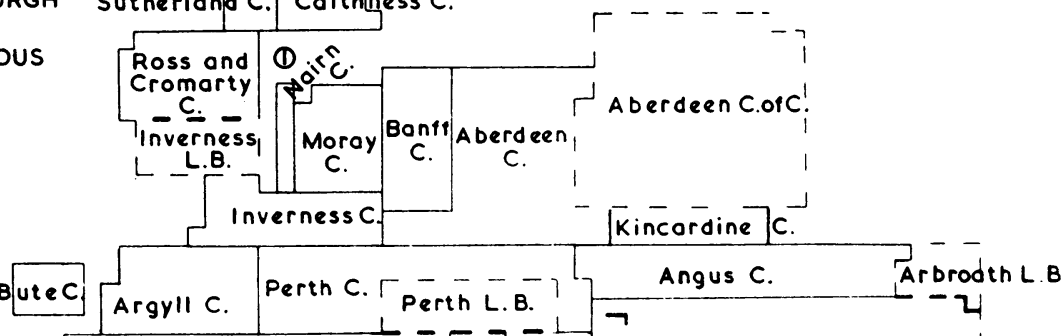
Arbrodth L B

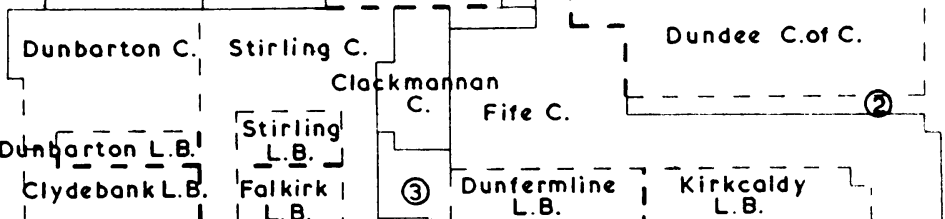

(4) $L \ldots \ldots-L^{\prime}$ L.B.

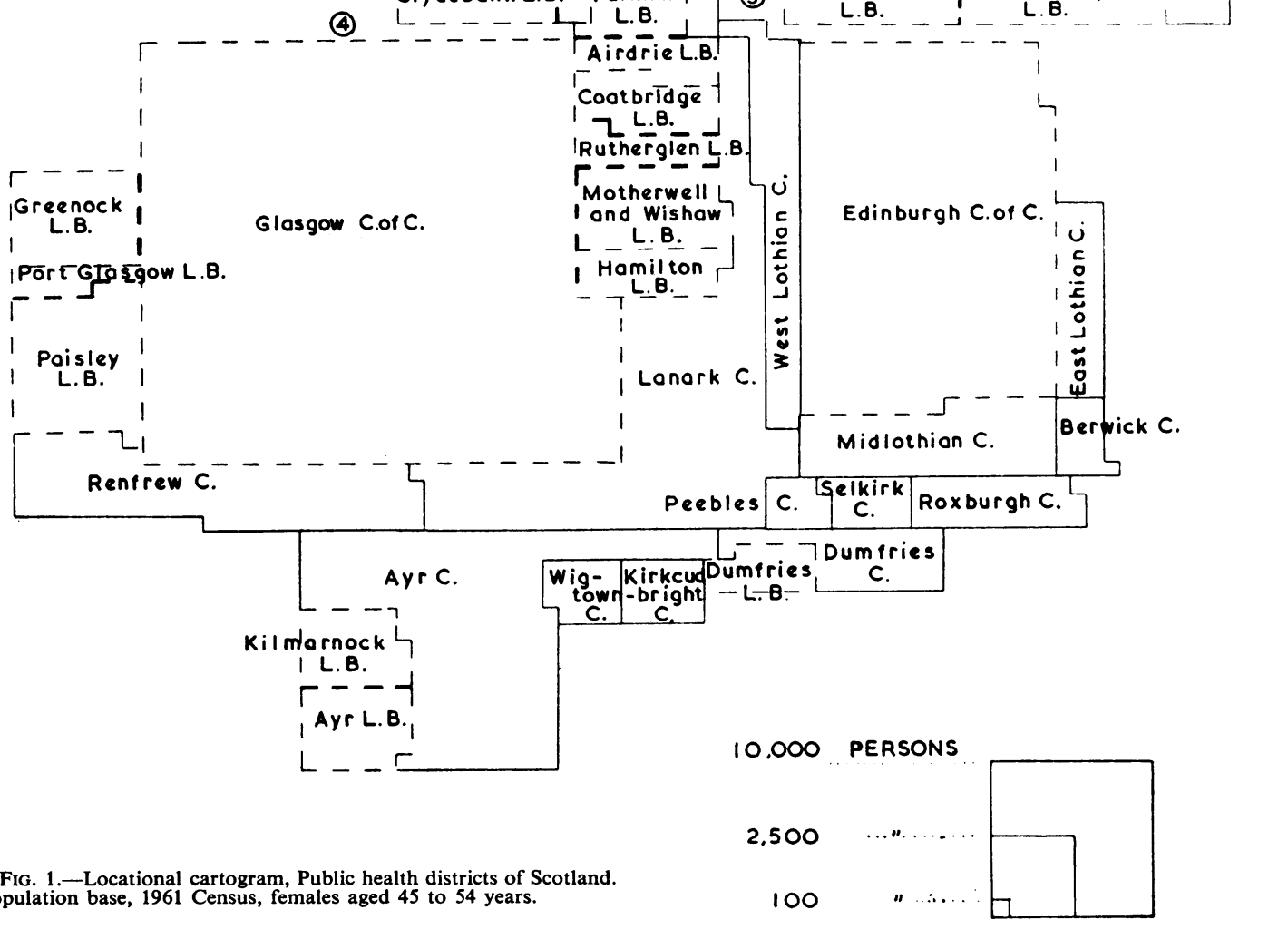


population in the age group $45-54$ years, will facilitate understanding of the following explanation:

(1) 1961 census population figures were taken for the 57 public health districts of Scotland for the 10-year age groups 35-44, 45-54, and 55-64, and for 35-64 combined for males and females separately. There were thus eight age-sex groups in all.

(2) A scale of 0.1 " square to the nearest 100 persons was selected as suitable for plotting the cartogram outlines onto arithmetic graph paper.

(3) The firths of Moray, Tay, Forth, and Clyde, were selected as prominent geographical features around which to build the cartograms. (These features penetrate markedly into Scotland and do much to determine the country's shape).

(4) The cities of Glasgow, Edinburgh, Aberdeen, and Dundee were given constant positions fronting onto their respective firths. As these cities are important population concentrations, their positions and size partially determined the positions of the other units. The firths and cities thus provided a framework of lines and areas common to each cartogram which helped to achieve similarity of final outline.

(5) To prevent the cartograms from becoming too complex in shape, a factor which can lead to difficulties of assessing the relative weighting to be given to individual units, the following conventions were adopted:

(a) No attempt was made to retain the geographical shape of administrative units; instead they were formalized into shapes based on rectangles. Consideration of Argyll with its small population, considerable north-south extent and often insular shape will show why this was necessary. Any attempt to retain its shape on a demographic map would have resulted in a fragmented narrow zone, the demographic weighting of which would have been difficult to assess.

(b) Geographical positions were modified where it was felt that this helped towards simplification of shape and construction, whilst as far as possible geographical contiguity of boundaries was maintained. For example, relative to Ayrshire, Wigtown has been given a north-westerly, as opposed to its true south-westerly, position.

(c) Where two or more large burghs occurred in a county, they, were grouped and indicated as noncontiguous. The alternative, to have distributed them throughout their county area, would have fragmented the latter and again have contributed to the problem of assessing demographic weighting.
In reality, no two large burghs in any county are more than 15 miles apart and in Lanark, which has five large burghs, both Airdrie and Coatbridge, and Motherwell and Hamilton are adjacent. Grouping does not therefore cause such a distortion as it might at first appear.

\section{RESULTS}

The same mortality data, calculated for all causes of death among females aged 45-54 years for the period 1959-63, is presented on the conventional map (Fig. 2, overleaf) and the cartogram (Fig. 3, overleaf). Clearly, impressions gained from maps are subjective and opinions will vary as to the relative value of different forms of presentation. Attention is drawn below to only the major points of difference between the two methods shown here in an attempt to illustrate the characteristics and, it is felt, the essential advantage of the demographic map.

As a first step it will be helpful to compare the locational cartogram (Fig. 1) with the geographical map (Fig. 2) so that familiarity can be gained with the conventions of the former and the alterations in the areal weighting of Scotland that result. In particular (Fig. 1):

(1) The north-west highland counties, north of Dumbarton and Stirling Counties, and the southern ones from Berwickshire to Wigtown, with their numerically small populations, are reduced in area, relative to Scotland as a whole.

(2) Conversely, the main areas of population concentration in west central Scotland and in eastern Scotland from Edinburgh northwards assume increased proportions.

(3) As a result of these changes, it is easier to appreciate the extent to which the population group used as a base for the cartogram is resident in the larger urban centres (Table) and in Glasgow in particular.

TABLE

SELECTED POPULATION TOTALS, 1961 CENSUS, FEMALES AGED 45-54 YEARS

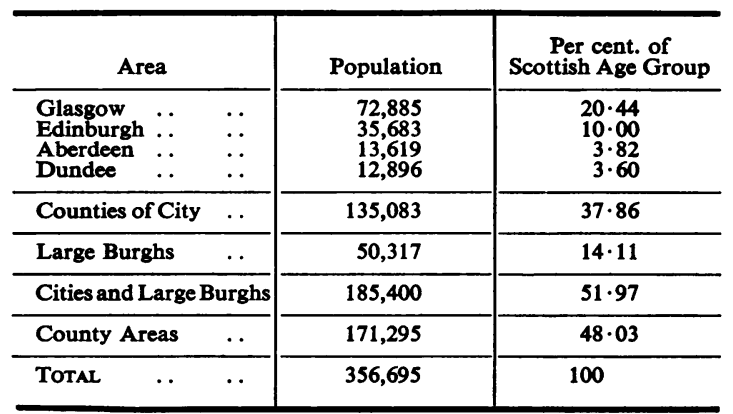


Comparison of the geographical distribution of the mortality rates on the two presentations (Fig. 2, and Fig. 3, opposite) can usefully be made at two levels. At the local level it is interesting to note the way in which the following are represented:
(1) Glasgow County of city and Kirkcudbright County, both being high mortality rate areas.

(2) Dundee County of city and Angus County, respectively high rate and low rate areas.

(3) The variable mortality experience in the large

RATES $/ 100.000$

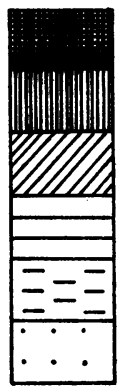

OVER 600

$550<600$

$500<550$

$450<500$

$400<450$

UNDER 400
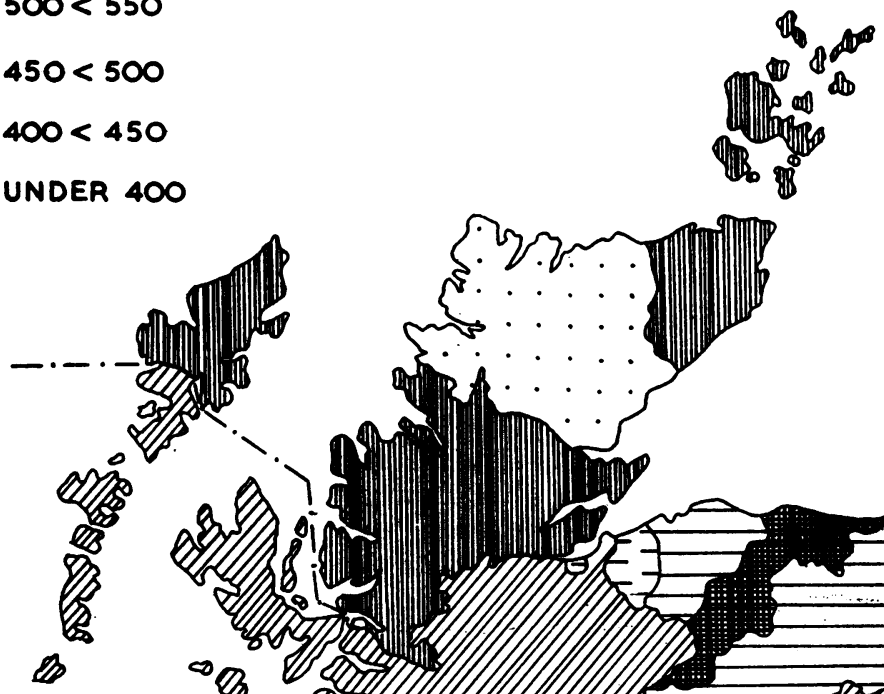

400
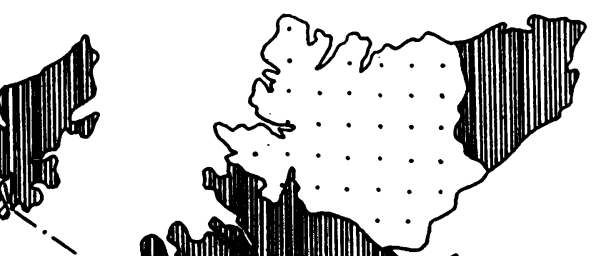

P
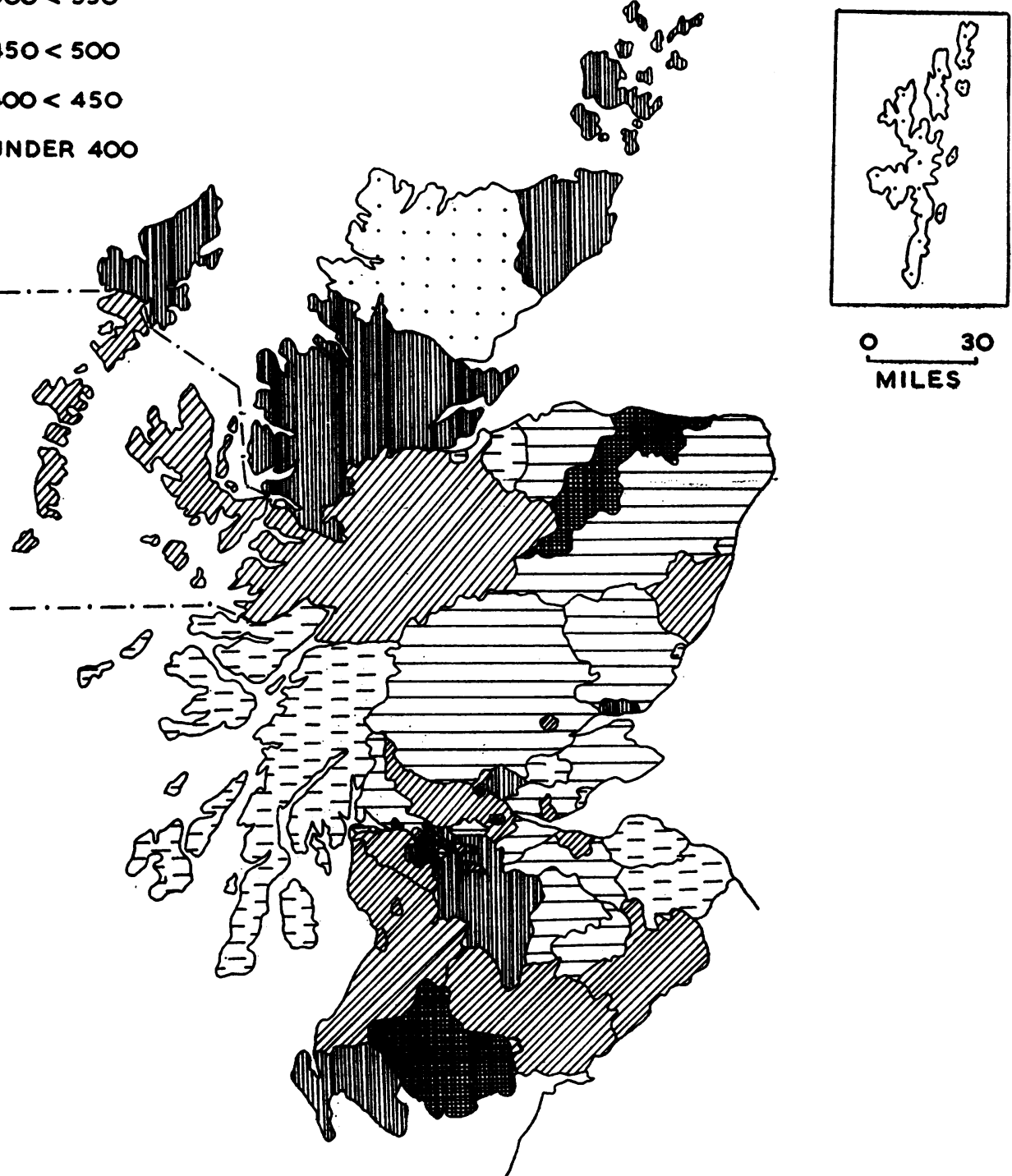

Fic. 2.-Average mortality rates 1959-63, all causes of death. Females aged 45 to 54 years. (Conventional map). 

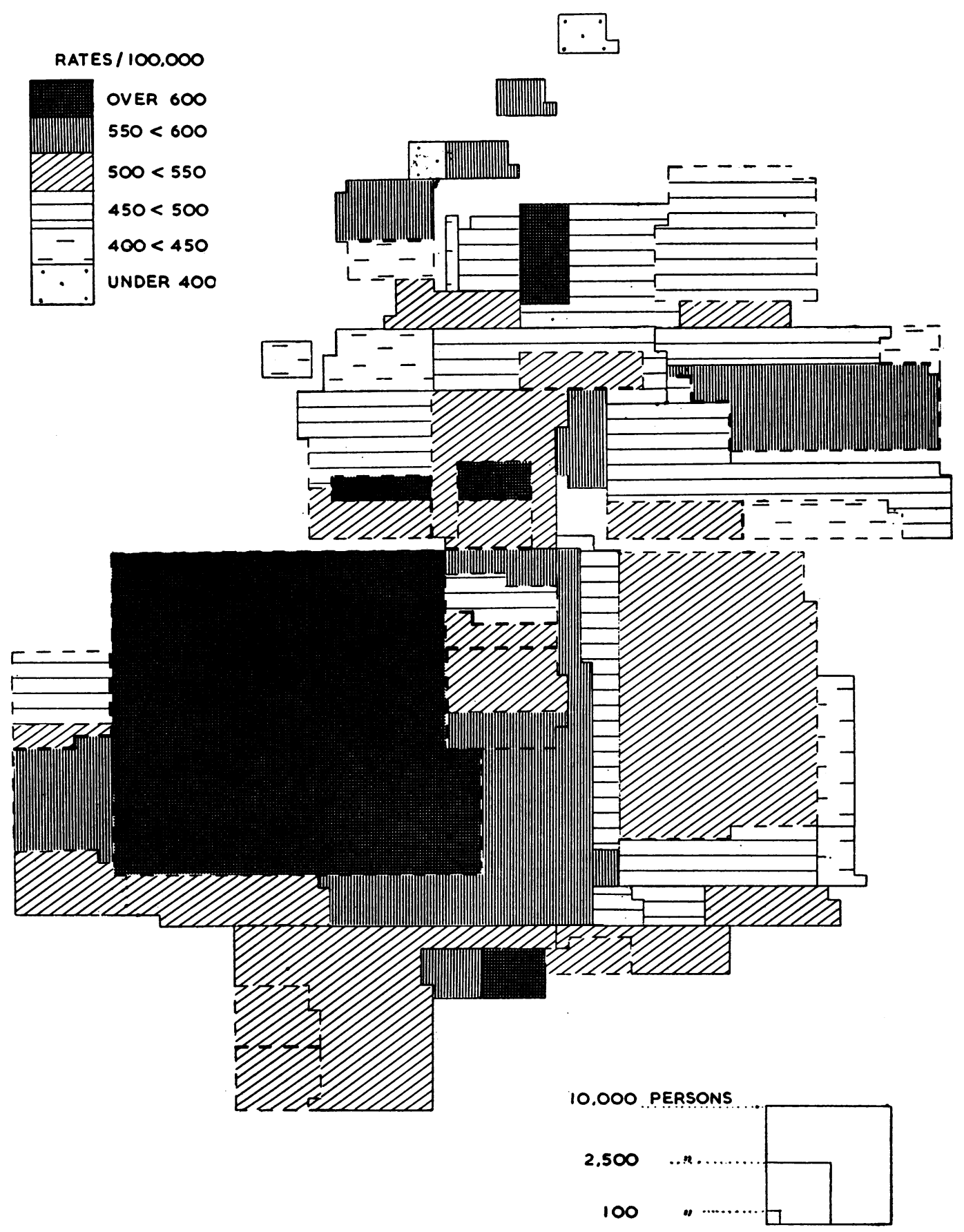

Fig. 3.-Average mortality rates 1959-63, all causes of death. Females aged 45 to 54 years. (Cartogram). 


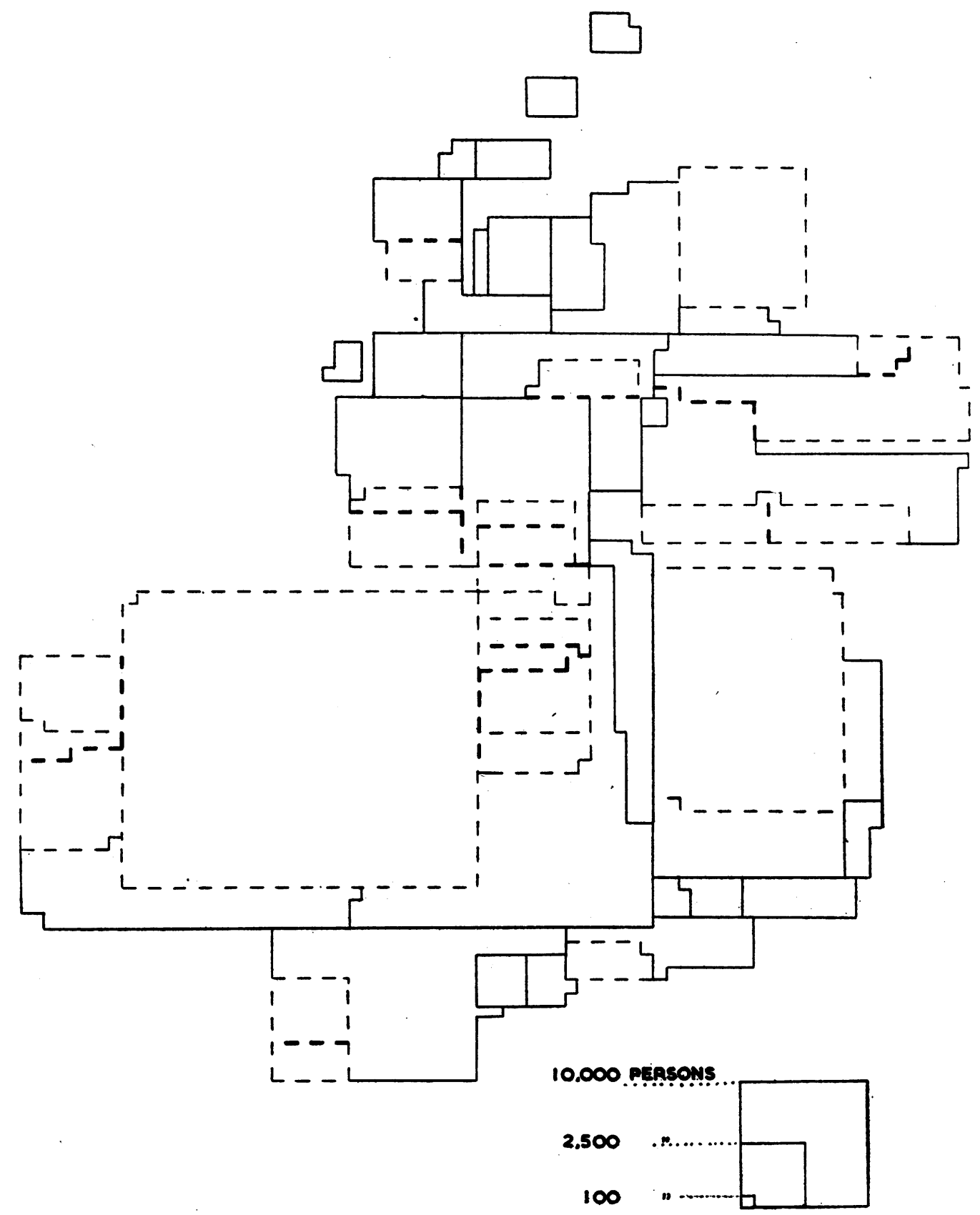

FIG. 4.-Age-sex specific cartogram (outline). Population base, 1961 census, males ased 35 to 44 years. 
burghs in geographical proximity to Glasgow. At the wider regional level, the following summary of the geographical pattern of mortality is obtained and, it is suggested, is easily recognizable on both presentations.

(1) Glasgow is the most prominent area of unfavourable mortality experience. Together with the large burghs of Stirling, Airdrie, Hamilton, Paisley, and Lanark County, it forms a high rate area in West Central Scotland. Within this area the large burghs of Greenock and Coatbridge stand out in marked contrast by virtue of their low mortality rates.

(2) No other concentrations of high mortality are found. Rather, a sporadic distribution of high rate areas occurs, including the rural counties of Orkney, Caithness, Banff, and Ross and Cromarty in the North, Wigtown and Kirkcudbright in the south, and the urban area of Dundee on the east coast.

(3) A zone of moderate to low mortality experience extends from Argyll and Bute, northeastwards to Aberdeen County and southeastwards to Berwickshire.

(4) All of eastern Scotland south of Aberdeen County, with the exception of Dundee, is thus a favourable area in terms of mortality experience in this sex and age group.

\section{Discussion}

The principal value of a map is that it enables the essential features of a distribution pattern to be quickly appreciated. The cartographic needs of different disciplines do, however, vary, and maps are of greatest value when designed to serve specific requirements. The cartograms presented above are illustrative devices especially suited to the needs of the epidemiologist working with areal data for, by their very nature, they correct the principal defect of the conventional map by illustrating the required dimension of population.

Perhaps the most encouraging feature is that, as a result of careful initial consideration of the major demographic and geographic features of Scotland, it has been possible to produce a demographic base-map which is simple enough in arrangement readily to allow geographic patterns to emerge. Further, the utility of the device is considerably increased by the fact that the eight different age-sex cartograms produced are easily visually comparable and that they all share a common set of conventions (cf. Fig. 1, and Fig. 4, opposite). It will be clear that such maps can be prepared for any area and any subsection of the total population, given the relevant population figures. It might be useful to consider the production of a national series of age-sex specific base-maps of this type having common shapes and conventions, for use in the presentation of areal data in epidemiological studies.

\section{SUMMARY}

Presenting disease rates on the conventional geographical base-map does not allow of weighting for local population differences. Development of the demographic map offers possibilities for relating disease rates both to local populations at risk and to geographic position. In an attempt to achieve these effects, age-sex specific cartograms were developed for Scotland based on 1961 census figures. Their construction is described and, by presenting the same mortality data on both the cartogram and the geographic base-map, an attempt is made to indicate the advantage of the former over the latter for the presentation of areal data in epidemiology.

I am indebted to the following: Dr Mary Fulton and Mrs Elspeth Semple for their kind permission to use the epidemiological data portrayed in this article, Prof. S. L. Morrison for his encouragement, Mr T. Edge of $\mathrm{J}$. Bartholomew and Company, Limited, for advice regarding the use of cartographic equipment, and Prof. Wreford Watson for kindly placing at my disposal the facilities of the Department of Geography in the University of Edinburgh.

\section{REFERENCES}

Hollingsworth, T. H. (1966). Map of Results of General Election, The Times, April 4, 1966. Late London Edition, p. 8.

Levison, M. E., and Haddon, W. (1965). Publ. Hlth Rep. (Wash.), 80, 55.

Sutherland, I. N. (1962). Brit. J. prev. soc. Med., 16, 30. 